\title{
Comunidade de aprendizagem profissional: tensões nos processos de desenvolvimento profissional de mentoras
}

\author{
Professional learning community: \\ tensions in mentors professional development processes
}

\author{
Comunidad de aprendizaje profesional: \\ tensiones en los procesos de desarrollo profesional de mentoras
}

\author{
ALINE DE MEDEIROS RODRIGUES REALI* \\ REgina MARIa SimÕEs PUCCINELli TANCREDI** \\ MARIA DA GRAÇA NICOLETTI MIZUKAMI***
} \begin{abstract}
$\diamond$
RESUMO

Por meio de uma pesquisa, pautada num modelo construtivo-colaborativo de interação pesquisadoras-professores, buscou-se identificar e compreender as tensões vivenciadas por formadoras (professoras experientes) ao atuarem como mentoras on-line de professoras iniciantes dos primeiros anos do ensino fundamental. $\mathrm{O}$ estudo fundamentase, teoricamente, sobre aprendizagem e desenvolvimento profissional da docência. Foram consideradas como dados de pesquisa as narrativas contidas nas correspondências virtuais entre mentoras e professoras iniciantes durante um período de quatro anos, bem como os registros das interações entre mentoras e pesquisadoras em encontros semanais. As tensões vivenciadas pelas mentoras foram identificadas e analisadas a partir de dúvidas, divergências, desacordos e resistências. Os focos considerados foram: configuração da identidade de mentoras como sendo a de formadoras; construção de uma base específica de conhecimento; desenvolvimento de atividades on-line do programa; domínio de conhecimentos específicos; experiência prévia como formadoras.

Palavras-chave: Programa de Mentoria Online. Comunidade de aprendizagem profissional. Mentores. Formadores. Desenvolvimento profissional da docência.
\end{abstract}

\begin{abstract}
Based on a constructive-collaborative model of teacher-researchers interaction, we sought to identify and understand the tensions experienced by experienced elementary schoolteachers acting as online mentors of primary novice teachers. The study is theoretically grounded on teaching learning and professional development literature. As research data it was considered the narratives contained in the virtual communication between mentors and novice teachers over a period of four years, as well as the records of interactions between mentors and researchers at weekly meetings. The tensions experienced by mentors were identified and analyzed considering their doubts, disagreements and resistances. In this paper we focus on mentors identity construction processes as teacher educators; the development of a specific knowledge base; the development of online activities of the mentoring program; the domain of mentors' expertise - specific and pedagogical content knowledge - and their previous experience as a teacher educators.
\end{abstract}

Keywords: Online Mentoring Program. Professional learning community. Mentors. Teacher educators. Teaching professional development.

\footnotetext{
*Doutora em Psicologia (Psicologia Experimental - USP). Professora titular da Universidade Federal de São Carlos. E-mail: <alinereali@ufscar.br>.

**Doutora em Educação pela Universidade Federal de São Carlos. Professora voluntária (associado - nível 01) na Universidade Federal de São Carlos e professora PPI da Universidade Presbiteriana Mackenzie. E-mail: <retancredi@gmail.com>.

*** Pós-doutora na Santa Clara University, Califórnia, Estados Unidos. Doutora em Ciências Humanas pela Pontifícia Universidade Católica do Rio de Janeiro. Professora adjunta III na Universidade Presbiteriana Mackenzie (Centro de Comunicação e Letras - Programa de Pós-graduação em Educação, Arte e História da Cultura) e e professora colaboradora junto ao Programa de Pós-graduação em Educação, área de Processos de Ensino e Aprendizagem, da Universidade Federal de São Carlos.E-mail: <gramizuka@gmail.com>.
} 


\section{RESUMEN}

Mediante una investigación, basada en un modelo constructivo-colaborativo de interacción investigadoresprofesores, se buscó identificar y comprender las tensiones vividas por formadoras (profesoras expertas) al actuaren como mentoras en línea de profesoras principiantes de los años iniciales de la educación fundamental a partir de su participación en una comunidad de aprendizaje profesional. Por tanto, fueron consideradas correspondencias virtuales entre mentoras y las profesoras principiantes que acompañaban por internet y los diálogos de mentoras e investigadoras en encuentros semanales. El proceso de constitución de esa comunidad fue largo y exigió una base de confianza bien establecida entre sus miembros. Se evidenciaron tensiones a partir de dudas, divergencias, desacuerdos y resistencias manifestadas por las mentoras y relacionadas a aspectos como: configuración de su identidad de formadoras; base de conocimiento para actuar como mentora; desarrollo de las actividades en línea del programa; dominio de conocimientos específicos; experiencia previa como formadora.

Palabras clave: Programa de Mentoría en línea (E-mentoría). Comunidad de Aprendizaje Profesional. Mentores. Formadores. Desarrollo Profesional.

\section{INTRODUÇÃO}

Neste artigo, analisam-se as principais tensões, compreendidas como oposição de ideias, sentimentos e ações, que resultaram em dúvidas, dilemas, divergências, desacordos, conflitos individuais e grupais. E que foram evidenciadas na construção e no desenvolvimento de uma "comunidade de aprendizagem profissional" responsável por um programa de mentoria, via internet, voltado para professoras iniciantes dos anos iniciais do ensino fundamental ${ }^{1}$. A investigação de tais aspectos se mostra relevante ao "reconhecer-se as diversas formas de esforço intelectual, físico, emocional e, em particular, apaixonado que [...] realizam os docentes" (DAY, 2007, p. 15), em especial, ao considerar-se o necessário comprometimento com seus estudantes e com o aperfeiçoamento da sociedade.

Salienta-se ainda que, no Brasil, políticas de apoio aos professores iniciantes são praticamente inexistentes, e poucas são as ações formativas voltadas para essa fase da carreira docente (GATTI, BARRETO e ANDRÉ, 2011) e para o desenvolvimento profissional de formadores de professores.

Os resultados obtidos podem servir de base para se compreender processos de aprendizagem e desenvolvimento profissional da docência e para proposição e avaliação de programas voltados à formação de professores experientes para atuarem como mentores. São apresentadas, inicialmente, as principais características do programa, que foi conduzido por professoras experientes (mentoras) em conjunto com as autoras e pesquisadoras da Universidade Federal de São Carlos. Em seguida, são explicitadas referências teóricas sobre aprendizagem e desenvolvimento profissional da docência que fundamentam a proposição do programa, características da investigação e seus objetivos, metodologia adotada, análise dos dados e principais resultados.

\footnotetext{
${ }_{1}^{1}$ Fapesp (ensino público), CNPq.
}

Participaram da pesquisa dez mentoras, selecionadas a partir dos seguintes critérios: mais de 15 anos de prática docente, experiência diversificada em situações cotidianas de sala de aula e assuntos da escola. As mentoras ofereceram processos formativos durante o período de quatro anos para 42 professoras iniciantes dos primeiros anos do ensino fundamental. As interações mentoras-professoras foram realizadas por meio de correspondência on-line, em ambiente desenvolvido para o Programa de Mentoria Online. Tiveram como eixo as dificuldades específicas identificadas e enfrentadas pelas professoras iniciantes. Tendo como foco as mentoras, objetiva-se, neste artigo:

1. Identificar as tensões, isto é, dúvidas, dilemas, divergências, desacordos, conflitos individuais e grupais que se apresentaram ao longo da construção e desenvolvimento do programa;

2. Compreender alguns efeitos das tensões identificadas sobre os processos de desenvolvimento profissional das mentoras participantes.

Trata-se de uma pesquisa-intervenção de natureza construtivo-colaborativa (KNOWLES e COLE, 1993), centrada na promoção de processos de desenvolvimento profissional de docentes e na investigação de tais processos.

\section{Programa de Mentoria - CARACTERÍSTICAS GERAIS}

Caracterizado por ações de formação continuada de professores, via internet, o Programa de Mentoria faz parte do Programa de Apoio aos Educadores: Espaço de Desenvolvimento Profissional (REALI e TANCREDI, 2003) e é desenvolvido no Portal dos Professores $<$ www. portaldosprofessores.ufscar.br>.

Destina-se a professores iniciantes dos primeiros anos do ensino fundamental (com até cinco anos de exercício da profissão) interessados em investir em seu 
desenvolvimento profissional. A iniciativa tem como propósitos: contribuir para a formação de professores reflexivos, estimulando um processo constante de autoavaliação das competências profissionais e a reorientação do seu trabalho; favorecer a autonomia dos professores, promovendo a melhoria da ação docente, tanto no desenvolvimento do currículo quanto na gestão do conhecimento e da classe; proporcionar apoio e assessoria didática aos professores, favorecendo seu bem-estar pessoal e profissional; facilitar sua adaptação e integração crítica ao sistema de ensino, à realidade da escola e da comunidade e a seus pares; ajudar os professores a superar incertezas, dúvidas, angústias e temores diante de dificuldades de várias ordens que surgem, em especial, nos anos iniciais da docência; contribuir para a permanência dos professores no magistério.

Caracteriza-se por ser a distância, via internet. O modelo adotado de mentoria tem como eixo metodológico a reflexão dos professores iniciantes sobre a própria prática, levando em conta as características da aprendizagem do adulto e os contextos de atuação profissional. Cada professora iniciante inscrita recebe a orientação de uma mentora (uma professora experiente) que a acompanha durante a vigência do programa. Este pode se realizar em dois módulos (um primeiro, com duração de 120 horas, ao longo de aproximadamente um ano; e um segundo, complementar, com a duração de 60 horas, ao longo de seis meses). O programa tem um currículo aberto, no qual as demandas indicadas pelas iniciantes são consideradas como ponto de partida do processo formativo e orientam todo o processo interativo mantido com as mentoras.

Três etapas configuraram a concepção, elaboração, desenvolvimento e avaliação do programa durante quatro anos. A primeira destas, de duração de três meses, referese à construção do programa pelas pesquisadoras e professoras experientes. Devido aos seus conhecimentos diversificados, essas profissionais apresentavam condições de aconselhar e orientar professores iniciantes; oferecer informações variadas; sugerir estratégias de ensino adequadas às demandas dos estudantes; propor soluções a problemas evidenciados em sala de aula e compartilhar experiências.

Esse processo tomou como base as concepções dessas futuras mentoras sobre ensino, aprendizagem, conhecimento, alunos, professor, escola, currículo etc., bem como o que qualificaram como necessário para desempenhar o papel de mentoras. Adicionalmente, foram delineadas as características básicas do Programa de Mentoria, definidos seus pressupostos, o "currículo", as atividades, a dinâmica, a duração. Para tanto, desenvolveram-se diversas atividades - entre estas, leituras e discussões de textos, estudos de casos, relatos (escritos e orais) de experiências profissionais etc.
Os seguintes temas foram abordados: a problemática vivenciada pelo professor iniciante; a necessidade de suporte educacional; a possibilidade de atendimento individualizado e em tempo adequado; o contexto de atuação; e o uso da internet como ferramenta formativa.

Numa segunda etapa, de duração de cinco meses, as futuras mentoras participaram de atividades formativas para atuar on-line, já que nenhuma dela tinha esse tipo de experiência prévia.

Com duração de três anos e meio, a terceira etapa foi caracterizada por atividades formativas destinadas às professoras iniciantes. A cada mentora foram atribuídas três a quatro iniciantes. Nessa etapa, foram mantidas as reuniões semanais entre as pesquisadoras e as mentoras, realizadas na universidade, com o objetivo de analisar as interações da semana e de discutir as ações a serem desenvolvidas para a semana seguinte. As reuniões constituíram espaço para análise de troca de ideias, referenciais, experiências e formas de enfrentamento das situações vividas. Representaram, igualmente, uma oportunidade para tomada de decisões teóricometodológicas, uma vez que se lidou com planejamento aberto durante todo o processo formativo e investigativo. Para a definição sobre a pauta de cada encontro, as mentoras enviavam para as pesquisadoras um relato semanal sobre as atividades realizadas com as professoras iniciantes, sob sua responsabilidade, acompanhado de um diário reflexivo. Considera-se que essas atividades diversificadas passaram a se constituir, ao longo do tempo, em ferramentas de promoção de novas aprendizagens profissionais e de investigação de como estas ocorrem. Trata-se, pois, de um espaço de pesquisa e intervenção.

A investigação adotou um modelo construtivocolaborativo de interação entre pesquisadores e professores, fundamentado nas contribuições de Cole e Knowles (1993) e Clark et al (1996 e 1998), com destaque para os seguintes aspectos: colaboração, problemas das práticas cotidianas, ênfase no desenvolvimento profissional, atenção ao tempo e ao apoio que os participantes da pesquisa - pesquisadores, mentores e professores iniciantes - necessitam para estabelecer comunicações abertas e diálogo. Apresentava, pois, característica dupla ao possibilitar, por um lado, construir conhecimentos sobre aprendizagem da docência e sobre formação de formadores de professores (mentores) e, por outro, promover intervenção no contexto em que as práticas (das iniciantes e das mentoras) ocorriam.

Os dados da pesquisa foram coletados nas reuniões semanais presenciais entre mentoras e pesquisadoras e gravados em áudio e vídeo. Fontes adicionais de dados foram constituídas de registros disponibilizados no ambiente virtual do programa: correspondências entre mentoras e professoras iniciantes, diários reflexivos das 
professoras e das mentoras, casos de ensino desenvolvidos. Narrativas de diferentes naturezas foram, portanto, as principais fontes de dados. Para análise desse material, verificou-se que o discurso do grupo de pesquisadoras e mentoras influenciava o desenvolvimento das diversas etapas do programa. Um dos desafios enfrentados foi o de analisar como essas interações promoviam o desenvolvimento profissional dos participantes, a construção de novas ideias e o compromisso com o programa (CARROL, 2005).

Como participantes do programa, as professoras iniciantes, sob orientação das mentoras, realizaram experiências de ensino e aprendizagem sobre temas relativos ao dia a dia das atividades docentes e da escola. Essas práticas podem ser compreendidas como um conjunto de ações planejadas pelas professoras iniciantes em conjunto com suas mentoras, a partir de assuntos, problemas, dilemas, elencados pelas primeiras como sendo de seu interesse. Representam processos circunscritos - que podem implicar ações dentro e fora da sala de aula relativas à compreensão de componentes curriculares ou de desafios propostos pelo dia a dia da escola e das políticas públicas (MIZUKAMI et al, 2010; REALI et al, 2014).

Ao investigar e promover os processos de aprendizagem profissional da docência das mentoras, foram adotadas como referência conceitual ideias que remetem ao caráter processual e social do aprender a ensinar e a ser professor; constatou-se que professores, dependendo da fase da carreira que se encontram, demandam ações formativas específicas; reconheceu-se o papel relevante das práticas nos processos de aprendizagem profissional da docência; definiu-se a importância da inquirição ou reflexão crítica como contexto para novas aprendizagens e dos papéis de comunidades de aprendizagem nos processos de desenvolvimento profissional. Ideias estas que são a seguir brevemente apresentadas. Destaca-se que, na presente discussão, entende-se que um mentor é um formador de professor.

\section{MENTORES, CONFIGURAÇÃO DE SUA BASE DE CONHECIMENTO E O PAPEL DAS COMUNIDADES DE APRENDIZAGEM}

Apesar de a área de pesquisa sobre formação de professores ser relativamente recente, há evidências de que o desenvolvimento profissional pode conduzir a melhorias nas práticas docentes e na aprendizagem dos alunos (COCHRAN-SMITH e FRIES, 2005). Está-se ainda, no entanto, começando a compreender o que e como os professores aprendem no processo de desenvolvimento profissional e o impacto das mudanças desses profissionais sobre a aprendizagem dos alunos.
Os marcos conceituais que têm fundamentado o debate atual sobre aprendizagem e desenvolvimento profissional da docência e o das políticas públicas nacionais e internacionais relacionadas a essa temática podem ser considerados os seguintes: base de conhecimento para o ensino; comunidades de aprendizagem; conhecimento pedagógico do conteúdo; conhecimento tecnológico pedagógico do conteúdo (TPAKC), no caso da docência, com o uso de tecnologias digitais; teorias pessoais dos professores; ensino como profissão; postura investigativa; instituições escolares como espaços privilegiados de formação; desenvolvimento docente ao longo das trajetórias profissionais.

Vaillant (2003), numa análise sobre a situação da formação de professores na América Latina, revela que tem sido comum encontrar-se docentes "mal preparados, mal administrados e mal remunerados, sendo muito difícil esperar que façam um bom trabalho" (p. 1). Essas deficiências nem sempre são percebidas pelos docentes e pouco têm sido exploradas a respeito dos formadores de professores $^{2}$ e sobre sua base de conhecimento, quadro que, aliado à ausência de políticas voltadas para a preparação formal desses profissionais, complementa um cenário preocupante.

A partir da consideração das demandas da sociedade atual, assim como de seus alunos, os professores e seus formadores devem aprender a trabalhar em ambientes dinâmicos que se alteram e nos quais os conhecimentos se constroem a partir de diferentes fontes e perspectivas. Compreender o que se deve aprender e o aprender a aprender são ações imprescindíveis para formadores, professores e alunos.

Ao se analisar o quadro geral dos formadores de professores em nosso país, constata-se que, quando estão vinculados a cursos de formação inicial e atuam em instituições de ensino formais (institutos superiores de educação ou cursos universitários), têm usualmente a responsabilidade de: assegurar uma preparação compatível com as funções profissionais a serem exercidas pelo futuro professor; certificar o professor; contribuir para formação de profissionais responsáveis, éticos, reflexivos e comprometidos com seus alunos. No caso dos formadores, não há nenhum tipo de explicitação sobre seu perfil profissional e tampouco a indicação da necessidade de formação pedagógica. Os formadores, algumas vezes, são especialistas em Metodologia do Ensino Superior,

\footnotetext{
2 Para Vaillant (2003), falar de formador supõe "assumir um conceito de alta dispersão semântica" (p. 22). Pode ser assim entendido: (1) sinônimo de docente e nesse caso a formação de formadores abarcaria todo campo de conhecimento que se entende por formação de professores em seus diferentes níveis; (2) profissional que forma docentes de diferentes níveis de ensino; (3) em um caso especial, seria o profissional de ensino que participa na formação inicial de docentes como tutor de práticas; (4) professor mentor que assessora e orienta os professores iniciantes.
} 
mestres ou doutores - em áreas específicas ou mesmo em educação. Mais recentemente, algumas iniciativas têm sido desenvolvidas nos cursos de pós-graduação, voltadas para a formação do docente do ensino superior por meio de estágios supervisionados da carreira docente (Programa de Estágio Supervisionado de Capacitação Docente-PESCD). No geral, porém, ensinar futuros professores não é objeto de maior atenção, e professores podem ser bacharéis, licenciados ou profissionais de uma área específica.

No caso de formadores vinculados às atividades e aos programas de formação continuada, encontra-se uma situação similar à anterior, exceto nos casos dos coordenadores pedagógicos e assistentes técnicos vinculados às redes de ensino em que são professores formadores licenciados. Mas, assim como um professor, a atuação de formadores ocorre em situações conflitantes, complexas e submetidas a forças múltiplas e contraditórias (KENNEDY, 2006). Suas práticas se pautam, geralmente, em conhecimentos construídos ao longo de suas trajetórias que, por sua vez, podem funcionar como "lentes" ou "filtros" (FAIRBANKS et al, 2010) pelos quais veem a aprendizagem, mas também orientam sua atuação. As demandas atuais sobre os docentes e seus formadores exigem que devam ser criativos e flexíveis de modo a aplicar seu conhecimento profissional de inúmeras maneiras às diversas situações que devem vivenciar, assim como devam ser capazes de planejar o seu próprio desenvolvimento profissional (KNOWLES, COLE e PRESSWOOD, 2008).

No geral, tendo em vista a formação de professores, predomina a ideia de que o domínio do conteúdo específico é a característica essencial para o exercício dessa função. Esta é, todavia, uma ideia limitada, porque conhecer um tema, (não consegui tirar a tarja preta) um assunto, um tópico não garante o seu bom ensino (MIZUKAMI et al, 2010). Além de dominar os conteúdos específicos, é imprescindível que adotem estratégias de ensino adequadas aos alunos, levando em conta seu nível de desenvolvimento, grau de motivação, características culturais, linguísticas, oportunidades de aprendizagem, recursos. É importante que saibam se relacionar com os pares, em busca da solução das dificuldades da atividade docente para a construção de práticas pedagógicas voltadas para um ensino de qualidade; que atuem de modo articulado e consistente com as características de sua comunidade escolar; e, ainda, que sejam capazes de promover o seu próprio desenvolvimento profissional e o de seus pares. Inegavelmente, a qualidade do sistema educativo depende de seus professores e de suas práticas pedagógicas, que por sua vez relacionam-se aos processos formativos ao quais foram/são submetidos e que podem ter impactos sobre a qualidade da aprendizagem dos alunos.
Para Shulman (1987), os professores devem apresentar uma base de conhecimento para o ensino que consiste em um corpo de compreensões, conhecimentos, habilidades e disposições que são necessários para que o professor possa propiciar processos de ensinar e de aprender. Essa base envolve conhecimentos de diferentes naturezas, todos necessários e indispensáveis para a atuação profissional. Não se trata de uma base de conhecimento fixa e imutável, mas de uma base que é continuamente alterada. Nos formadores como nos professores, essa base deve ajustar-se ao contexto, ou seja, "a onde e a quem se ensina (...). Os formadores terão de adaptar seu conhecimento geral da matéria aos estudantes e às condições particulares do instituto de formação" (VAILLANT, 2003, p. 30).

No caso de mentores, devido às características de sua atuação, há evidências de que necessitam dispor de uma base de conhecimento multidisciplinar complexa, que implica um sistema altamente organizado (PUTNAM e BORKO, 1986) em ao menos dois níveis: um relacionado ao seu papel de formadores de professores iniciantes, e outro concernente ao ensino dos alunos desses professores (ACHINSTEIN e ATHANASES, 2005). Nos processos de aprendizagem e de construção da identidade de formador, os professores se deslocariam de uma posição em que são práticos de primeira ordem - pois exercem a docência de um conteúdo e em um contexto escolar - para uma nova posição, em que são práticos de segunda ordem, uma vez que para ensinarem outros professores se pautam primordialmente em seus conhecimentos e experiências anteriores sobre o ensino (MURRAY e MALE, 2005). Além disso, a identidade docente (de professor dos anos iniciais, por exemplo) deve ceder lugar à outra, de formador de professores iniciantes.

Tais profissionais necessitam, pois, a partir de uma base complexa de conhecimentos e práticas profissionais, apresentar uma visão multifocal em que, simultaneamente e de modo articulado, sejam capazes de, permanentemente, considerar os professores iniciantes e seus alunos e os contextos nos quais atuam, os processos de aprendizagem da docência aos quais são submetidos - mentores e professores iniciantes - e variáveis que intervêm em tais processos, tais como as limitações e dificuldades que podem advir da comunicação on-line, tendo em vista a característica do programa em pauta.

Semelhantemente à posição de Darling-Hammond e Baratz-Snowden (2005), assume-se, como posição teórico-metodológica, o desafio de se formar bons professores para cada sala de aula por meio de oferta de processos formativos pertinentes à contemporaneidade caracterizada por mudanças aceleradas. Tomando como base os autores citados, são enfatizados três eixos essenciais à constituição de uma base de conhecimento 
para a docência, que incluam conhecimento sobre: a) os alunos, seus processos de desenvolvimento e respectivos contextos socioculturais, envolvendo conhecimentos sobre aprendizagem, desenvolvimento humano e aquisição e desenvolvimento da linguagem; b) a matéria que os professores ensinam e o currículo compreendido em seus objetivos educacionais mais amplos; c) o ensino de diferentes matérias para diferentes alunos, bem como de formas de avaliação e de manejo de sala de aula. Três pontos que se intersectam numa visão de prática profissional e estão inseridos num contexto mais amplo de ensino como profissão e aprendizagem docente em uma sociedade democrática. Essa base de conhecimento é dinâmica, está em constante transformação e envolve aprendizagem individual e coletiva, bem como investimentos de natureza institucional, profissional e pessoal. É nessa perspectiva que as atividades desenvolvidas no Programa de Mentoria devem ser entendidas, objetivando oferecer processos formativos que possibilitem, ao professor iniciante, condições para superação - nos contextos específicos de suas vidas profissionais - de três situações identificadas por Hammerness et al. (2005) características da formação inicial: 1으 "aprender a ensinar" implica os professores compreenderem o ensino de maneiras diversas daquelas que aprenderam em suas experiências como estudantes; $2^{\text {o) }}$ oferta de condições é fundamental para que os docentes, em seus anos iniciais, não apenas desenvolvam habilidades de "pensar como professores", mas iniciem a construção de postura investigativa em relação às práticas iniciais em contextos específicos; $3^{\circ}$ ) vivência e análise da complexidade da profissão se fazem necessárias em situações escolares contextualizadas.

Fundamentado nas contribuições sobre aprendizagem e desenvolvimento profissional da docência, o Programa de Mentoria foi concebido tendo como eixo formativo e investigativo a construção de postura investigativa, tanto das mentoras quanto das professoras iniciantes. Postura investigativa é concebida por Cochran-Smith (2003) como uma estratégia formativa importante. Envolve a consideração de hipóteses, valores, conhecimentos profissionais e práticos, contextos das escolas, condições objetivas de trabalho, aprendizagens dos professores. Para a autora, a postura investigativa é uma perspectiva intelectual, uma forma de inquirir, de dar sentido e de estabelecer relações entre o trabalho diário aos trabalhos dos pares e a contextos sociais, históricos, culturais e políticos mais amplos. Pressupõe análise constante de processos formativos, descrição de práticas pedagógicas em seus múltiplos determinantes e variáveis, e realização constante do movimento teoria-prática-teoria. CochranSmith (2003, p. 24) concebe conhecimento local como "um processo de construção, questionamento, elaboração e crítica de referenciais conceptuais que ligam ação e proposição de problemas tanto ao contexto imediato quanto a temas sociais, culturais e políticos mais amplos". A autora ressalta que os formadores sejam capazes de trabalhar com certezas, incertezas, dilemas e problemas e que reconheçam que a investigação não só surge de questões que desafiam o sistema, mas também gera essas questões, envolvendo aprendizagens e desaprendizagens.

Em muitas circunstâncias, constata-se que professores necessitam do apoio de seus pares e com frequência é possível promover a construção de uma "comunidade de aprendizagem" (ou comunidade de prática) compreendida como um grupo de profissionais que, ao interagirem, modificam ou aprendem novas ações e conhecimentos e transformam suas identidades profissionais.

No caso da docência, tais comunidades podem ter um peso substancial na responsividade de professores às demandas originadas pelas políticas educacionais, no seu engajamento na construção de condições de ensino mais adequadas para seus alunos e, consequentemente, nas mudanças em suas práticas docentes (MIZUKAMI et al, 2010). Destaca-se que uma comunidade de aprendizagem difere de um mero grupo de pessoas trabalhando em torno de um objetivo comum. Um dos aspectos distintivos diz respeito ao fato de a primeira implicar a negociação do significado do trabalho realizado por meio das aprendizagens e a identificação de um membro com os demais. De acordo com Gallucci (2003), as comunidades de prática "criam, expandem e trocam conhecimentos sobre suas práticas, assim como desenvolvem suas capacidades individuais" (p. 15).

Em função dessa característica ativa de participação de professores em atividades de natureza colaborativa, as aprendizagens derivadas podem ocorrer ao menos em dois níveis inter-relacionados. Por um lado, há aprendizagens no plano individual que envolvem a ampliação da base de conhecimentos e que podem ser acionadas em diversas circunstâncias. Por outro lado, no plano coletivo, na construção partilhada de conhecimentos, dada a participação ativa em processos de aprendizagem coletivos, há ênfase na situação, no contexto, na interação. Além desses níveis, pode-se acrescentar a possibilidade de serem construídas aprendizagens organizacionais pelas escolas às quais os professores estão vinculados.

As aprendizagens em grupo podem ocorrer de diferentes formas, como, por exemplo: sem instrução direta (quando não há planos instrucionais que orientem e sistematizem a construção de conhecimentos em circunstâncias em que problemas reais são discutidos); a partir do estudo de casos que representem problemas reais; pela apresentação, por parte dos pesquisadores ou mesmo dos professores, de um plano de ação a ser 
analisado e até desenvolvido, ou mesmo a partir da participação ativa num programa formativo como o considerado no momento. A construção de comunidades de aprendizagem envolve esses processos e demanda tempo, pois exige que os professores participantes tenham oportunidade de expor sua base de conhecimentos e concepções, trabalhem em conjunto, partilhem objetivos, troquem ideias, negociem responsabilidades e decisões (GALLUCCI, 2003). Nessas circunstâncias, entende-se que os participantes da comunidade colaboram reciprocamente para o desenvolvimento profissional de cada um e enriquecem-se mutuamente.

Para se caracterizar como uma comunidade de aprendizagem, é essencial que a comunidade vá, ao longo do tempo, construindo uma identidade grupal, definindo normas de interação, compreendendo e aceitando as diferenças individuais, desenvolvendo, de forma negociada, a compreensão de que a aprendizagem docente e a aprendizagem dos alunos são processos interrelacionados e que deve haver uma responsabilização coletiva pelo crescimento individual de cada um. Uma comunidade profissional forte é capaz de promover o aprendizado e a melhoria das práticas de ensino. Nesses casos, os professores, ao participarem de grupos que apresentam objetivos comuns, têm possibilidade de trocar ideias, negociar responsabilidades e definir papéis; expor suas bases de conhecimento e práticas de modo a conceber o ensino de outras maneiras. Ao trabalharem em conjunto, os professores podem estar contribuindo para o crescimento profissional e enriquecimento mútuos. Além disso, de acordo com Wenger et al. (2009), é possível, nessas circunstâncias, "aprender para a vida, ainda que demande esforços e nem seja nossa intenção, mas sempre envolve quem somos, o que fazemos, o que buscamos conectar e aspiramos nos tornar" (p. 4).

\section{TENSÕES NOS PROCESSOS DE DESENVOLVIMENTO PROFISSIONAL DE MENTORAS}

No Programa de Mentoria, contexto da presente análise, observou-se, ao longo de seu desenvolvimento, a manutenção de um diálogo articulado entre pesquisadoras e professoras mentoras voltado para a construção de novos conhecimentos e também para a busca de soluções de problemas relacionados ao dia a dia das iniciantes acompanhadas. As mentoras, ao longo do tempo, puderam examinar criticamente a sua atuação com as professoras iniciantes; desenvolver e implementar intervenções e avaliá-las; e promover seu desenvolvimento profissional e a construção de novos conhecimentos (HARGREAVES, 1999), assim como as pesquisadoras.
A análise do processo de interação das mentoras e pesquisadoras revelou que aos poucos foi sendo forjada uma comunidade de aprendizagem da docência e os indicadores apontados por Grossman et al. (2000) foram identificados: a construção de uma identidade grupal e de normas de interação; a busca de soluções; a compreensão de que os objetivos do grupo consistem em acompanhar as professoras iniciantes, mas também as mentoras em suas dificuldades; e que todas as participantes são responsáveis tanto pelos processos formativos das professoras iniciantes quanto de seus próprios. Observou-se que o grupo se fortaleceu e se comprometeu com aprendizagens recíprocas.

Esse foi um processo longo, que exigiu o estabelecimento de uma base de confiança comum permeado pela apresentação de alguns dilemas, dúvidas, divergências, desacordos, resistências, conflitos individuais e grupais compreendidos como tensões que se examinam a seguir:

\section{- Ser professor $\times$ ser mentor}

A atuação de uma dessas profissionais aponta para uma releitura pessoal do Programa de Mentoria de modo diverso ao estabelecido pelo grupo. Nesse caso, a professora assumiu um papel de apoio emocional em relação às professoras iniciantes acompanhadas, em lugar de incentivo à reflexão dessas profissionais sobre a própria prática, levando em conta as características da aprendizagem do adulto e os contextos de atuação profissional. A não aderência dessa mentora à identidade de mentora delineada pelo grupo - e construída pela maioria das mentoras - esteve relacionada ainda a atitudes ambivalentes ou negativas com relação às atividades propostas no programa. Exemplos dessas condutas foram: chegar em atraso e faltar aos encontros presenciais com as outras mentoras e pesquisadoras, sem avisar previamente ou sem oferecer justificativas posteriores; demorar excessivamente em responder para as professoras iniciantes que acompanhava.

No caso de outra professora, evidenciou-se uma participação tímida no grupo, o que foi notado por suas raras palavras nos encontros presenciais e também pela pouca exposição de suas ideias e sentimentos nos diários reflexivos. Em menos de seis meses após o início das atividades de mentoria com as professoras iniciantes, essa professora comunicou sua saída para as pesquisadoras, conforme mensagem a seguir:

\footnotetext{
Aline, Regina e Graça,

Procurei me engajar no Programa de Mentoria, não faltando às nossas reuniões, participando ativamente das aulas de informática, fazendo os diários reflexivos, recebendo e enviando mensagem
} 
a minha $\mathrm{Pi}^{3}$ (...) Sinto que tudo isso é pouco diante da colaboração, empolgação e entusiasmo das outras participantes. Acredito que todos os meus esforços foram pequenos para o Programa, mas tenham certeza que fiz o máximo que estava ao meu alcance. Gosto de me dedicar de corpo e alma em tudo que me disponho a fazer. E no Programa estava me sentindo de mãos atadas. Não tenho o conhecimento teórico necessário para estar discutindo e colaborando com o grupo e mesmo com minha professora iniciante.

Quero me desligar do Programa, admiro quem se dedica às pesquisas e sei que para isto é necessário disponibilidade de tempo e muito estudo.

Sinto-me realizada quando acordo de manhã e sei que logo mais estarei com os meus alunos. É esse prazer que me impulsiona a buscar novos conhecimentos através de cursos que realizo e estar atenta às necessidades individuais de cada um.

Helena

As atitudes dessas mentoras geraram, no grupo, sentimentos de solidariedade e apoios expressos nos encontros e mensagens, mas também de desconforto ao longo do tempo, uma vez que foram aos poucos sendo percebidas pelas pesquisadoras e mentoras como não apresentando perfil ou disposição para exercerem a função de mentoras e para se ajustarem às normas e aos objetivos estabelecidos para o programa. Não se mostraram, de acordo com Day (2007), "apaixonadas", com força motivacional suficiente para demonstrarem "energia, determinação, convicção, compromisso e, ainda, obsessão" (p. 27) em dar conta dos propósitos e metas estabelecidos pelo programa. Embora esses aspectos fiquem evidentes na despedida de uma delas transcrita anteriormente. Supõe-se que a saída do programa se deveu ao desenvolvimento insuficiente da base de conhecimento para ensinar professores iniciantes a ensinar, o que teria comprometido possivelmente a construção da identidade de formador necessária para o desempenho adequado das atividades previstas.

No caso das demais mentoras, os conhecimentos foram explicitados/objetivados paulatinamente e sofreram efeitos dos contextos ao qual estavam expostas (o da interação virtual com as professoras iniciantes e o das interações presenciais com as outras mentoras e pesquisadoras). Os contextos de utilização dos novos conhecimentos (os de atuação das professoras iniciantes e também os de sua própria atuação como mentora) foram apontados pelas mentoras como espaços de reformulação de antigos conhecimentos. Observou-se, nesses casos, a constituição de uma base de conhecimento multidisciplinar nos dois níveis apontados por Achinstein e Athanases (2005) e Murray e Male (2005).

\footnotetext{
${ }^{3} \mathrm{Pi}-$ professora iniciante.
}

\section{- Formador experiente $\times$ formador iniciante}

Nos processos de adaptação de suas identidades prévias de professoras para o novo papel de formadora (mentora) e no desenvolvimento de um corpo de conhecimentos profissionais específicos (ensinar professores iniciantes), foi marcante a influência das experiências anteriores como formadoras. Com frequência, algumas destas sem experiência se reportavam às situações anteriormente vivenciadas por outras mentoras como uma referência a ser considerada.

Segue excerto de uma mentora que, em uma reunião, solicitou o auxílio de outras com experiências prévias como formadoras:

Carol: Eu estou com dificuldade de trabalhar com minha Pi Alessandra e gostaria de socializar com o grupo. Pedir ajuda, pois a gente tem que reconhecer nossos limites. Eu caí numa armadilha que eu mesma armei. Pedi o planejamento para ela e agora não sei como abordar porque há muitos problemas. Quero pedir ajuda a Dora e Maria Imaculada que são especialistas. Elas já deram o curso Letra e Vida, estão mais atualizadas do que eu, assim como outras de vocês que já fizeram esse curso, o Mão na Massa etc. Eu quero ajuda porque não sei se consigo continuar sendo mentora, não quero comprometer o trabalho do grupo. Todos os cursos que pude fazer para melhorar minha formação eu fiz, mas sei que ainda tenho muito o quê e para aprender.

Apresenta-se outro exemplo sobre a importância atribuída pela mentora Maria Imaculada, uma formadora experiente, à experiência de outras mentoras em um de seus diários reflexivos:

(...) conviver com outras mentoras mais experientes favorece a incorporação de práticas bem-sucedidas que contribui para melhorias e mudanças na minha atuação como formadora. Tenho certeza de que ao participar e colaborar com o desenvolvimento do Programa de Mentoria tenho clareza e confiança na minha capacidade de superar desafios ao ir muito além do que realmente pensaria ser capaz ao acreditar que poderia assessorar, via internet, professoras de anos iniciais em início de carreira (...). (Maria Imaculada)

Os conhecimentos de outras mentoras foram, portanto, ferramentas relevantes para a aprendizagem daquelas que não dispunham de experiências anteriores como formadoras (Carol) assim como para quem já dispunha de tais vivências (Maria Imaculada).

Segundo os dados, há diferenças nas bases de conhecimento entre as mentoras ao considerarem-se as experiências prévias como formadoras. Possivelmente, as 
formas de enfrentamento das dificuldades e dos dilemas da prática e a manutenção da motivação diferem entre as mais experientes e as iniciantes (DAY e GU, 2009). Assim como certamente possuem maior domínio dos conhecimentos, são mais flexíveis, dispõem de um quadro de referências mais amplo para lidar com as demandas, gerando maiores e melhores oportunidades para aprendizagem das professoras iniciantes que acompanham (VILLEGAS-REIMERS，2003; BERLINER，2001; PACHECO e FLORES, 1999).

\section{- Interação on-line $\times$ contatos face a face}

No primeiro ano do programa, predominava no grupo um sentimento coletivo de receio das mentoras com relação ao desenvolvimento da interlocução via internet - exclusivamente por meio de trocas de mensagens eletrônicas - com as professoras iniciantes e o seu potencial de auxílio. Esse tipo de preocupação levou algumas mentoras a realizar algumas visitas a professoras iniciantes que acompanhavam.

Comentamos que os encontros presenciais são válidos e necessários porque sentimos necessidade de constatar, observar o trabalho das professoras e o desempenho dos alunos e se tudo ocorre realmente de acordo com o relato feito pelas $\mathrm{Pi}$. Na verdade, fica a impressão de que o que está sendo descrito/refletido por elas sob seu ponto de vista pode ser uma avaliação equivocada. Não acredito que uma simples visita vá resolver essa dúvida e permitir uma constatação real, mas pelo menos poderemos conversar com a $\mathrm{Pi}$, com os alunos, olhar seus cadernos e materiais, sentir o ambiente de aprendizagem, e a confiança da professora. Temos que ter cuidado para que esse encontro não fique marcado como uma forma intencional de fiscalização e cobrança de resultados, o que seria altamente improdutivo e desaconselhável. Acho que terá que ter um caráter formal e também descontraído, sem comentários que possam comprometer a postura da Pi. (Maria Imaculada)

Eu me lembrei, de um dos contatos que tive com a minha Pi..., em que eu fiquei na dúvida se ela estava sendo irônica ou se realmente era sinceridade, o fato de às vezes não estarmos 'olho no olho' ou até mesmo escutando a voz da pessoa, realmente pode nos passar impressões que não são reais. (Manuela)

Aos poucos, na medida em que as mentoras passaram a atuar com menos receios e maior domínio em relação à modalidade a distância, às ferramentas tecnológicas e às narrativas, ficaram mais à vontade, com maior segurança, dispensando as visitas às professoras iniciantes.

A princípio, temia pelo modo de atendimento, até então inédito para mim: o atendimento 'online'. (...) Parecia-me que os contatos via Internet seriam 'gelados', 'distantes'. Aos primeiros atendimentos, essa sensação ainda persistia. No decorrer do processo, esses sentimentos foram se dissipando, até que me senti realmente à vontade $\mathrm{e}$, assim, as trocas de mensagens foram tomando consistência e, hoje, o atendimento é bastante claro, conciso, produtivo. (Liz)

Tendo em vista que o conhecimento pedagógico do conteúdo se articula com as maneiras pelas quais as mentoras auxiliam as professoras iniciantes a compreender um determinado conteúdo e em tal processo se destacam as representações, sua organização, o que é simples ou difícil de ser aprendido entre outros (MARCELO, 2013), a percepção das mentoras sobre as professoras iniciantes se mostrou influenciada pelo fato de as interações serem virtuais. O que ocasionava, no início, dúvidas, inseguranças e incertezas.

\section{- Ensinar a ensinar: dar o peixe $\times$ ensinar a pescar}

Considerando uma das características principais do programa, ou seja, ao adotar uma perspectiva de atendimento às necessidades formativas individuais das iniciantes, o resultado foi um currículo aberto, mas que não poderia se configurar como a oferta de conselhos pontuais, o que trouxe para o grupo das mentoras algumas dúvidas e anseios. Seguem algumas reflexões que apontam para os dilemas das mentoras com relação a essa característica do programa.

A maioria das pessoas está acostumada com um modelo de curso, de um estudo curricular, de uma aprendizagem gradativa e sistematizada. Parece complicado estar construindo a sua própria trajetória. Parece que é difícil identificar as próprias necessidades, refletir, problematizar, pedir orientação. Na maioria das vezes, não são consideradas as necessidades, as diferenças de quem precisa aprender. Quem ensina é que deve saber o que, como e quando ensinar. Somos conduzidos por um caminho de aprendizagem que nem sempre corresponde aos nossos interesses. Quando é oferecida a oportunidade de expressarmos nossas necessidades, dúvidas, não sabemos como fazer, não estamos acostumados, exige muito esforço. Entendo que não está sendo tão fácil para nossas Pi. (Carol)

(...) Precisei entender e fazê-las entender que o programa é muito mais do que um programa de ajudas pontuais; fazê-las compreender que estamos construindo com elas, em parceria, as soluções para um determinado problema, que não daríamos as soluções prontas; conseguir ser menos diretivas, saber ouvir mais, sugerir, questionar (...). (Maria Imaculada)

(...) Trabalhar com um currículo aberto realmente é um fator positivo porque favorece a abordagem de conteúdos que atendam às necessidades e interesses de sua Pi. No entanto, pode se tornar uma 'faca de 
dois gumes' quando se vai trabalhando situações pontuais que vão surgindo no dia a dia da sala de aula e você pode surgir como "bombeiro que fica apagando incêndio" a todo momento e não é esse o objetivo do programa. Gerenciar essa questão é importante para não cair em uma cilada. (...) 'Dar o peixe ou ensinar a pescar?' Esse é um dilema constante na interação virtual porque a questão do tempo é um dificultador nessa relação a distância, já que o retorno, às vezes, é demorado por conta de problemas que sempre surgem, principalmente com o computador. Há também o tempo que se gasta com o registro escrito, que necessita ser cada vez mais elaborado e sistematizado com paciência, habilidade e competência. Diante disso, a ansiedade toma conta e temos pressa de ver resultados. Temos que nos controlar para não dar 'receitas prontas' ao determinar quais atividades são adequadas para serem desenvolvidas pela PI na sala de aula. Problematizar, instigar, questionar, tematizar, fazê-las pensar sobre sua prática para que reflitam sobre ela, antes, durante e depois é um ato que exige cuidado e atenção. (Dirce)

As mentoras investigadas apontaram domínio sobre inúmeros aspectos referentes ao conhecimento pedagógico geral, compreendido como princípios e formas de aprendizagem (SHULMAN, 1986), bem como os tempos exigidos pelas professoras iniciantes. Observou-se ainda que ensinar a partir de um currículo aberto pressupôs conhecer bem cada professora iniciante e suas necessidades formativas e também conhecer os alunos, seus métodos de aprendizagem e conhecimento. Esse processo resulta claramente no entendimento pedagógico dos conteúdos ensinados pelas mentoras, que foram sendo construídos à medida que identificavam o que e como as professoras iniciantes deveriam aprender.

\section{- Domínio de vários conteúdos $x$ domínio de áreas específicas}

Outro aspecto tenso observado diz respeito ao domínio dos conteúdos específicos. As mentoras apresentavam diferentes formações e domínios também variados. No início do processo de mentoria, observouse que algumas mentoras apresentavam dificuldades em definir ou expressar, com clareza, as lacunas de sua base de conhecimentos, o que em parte dificultava as trocas e os auxílios. De acordo com Hargreaves (1999), os professores geralmente não têm clareza do tipo de conhecimento que dispõem/possuem e em consequência não o compartilham. O exame cuidadoso do conhecimento - como muitas vezes ocorreu nas reuniões entre mentoras e pesquisadoras e ainda por meio de trocas de correspondências - possibilitou a distribuição do saber nos diferentes membros do grupo, resultando na construção de novos conhecimentos. Constatou-se que esse processo ocorre mais facilmente com os conhecimentos explícitos porque já haviam sido decodificados anteriormente pelo grupo de mentoras ou porque são facilmente expressos em palavras. Entretanto, considerando que parte do conhecimento do professor é tácito, e difícil de ser examinado em sua totalidade, investiu-se na condução do Programa de Mentoria, na promoção de atividades que possibilitassem o estabelecimento de uma cultura colaborativa e que encorajasse a sua expressão, a partilha de ideias e a identificação das lacunas existentes.

\begin{abstract}
Regina T sugeriu que Dirce socializasse a experiência de ensino-aprendizagem que está desenvolvendo com Alessandra sobre 'correção de texto', 'coerência e coesão' e 'paragrafação' para o grupo, pois vai ao encontro das dificuldades manifestadas por Cássia e em momentos anteriores manifestados por outras mentoras (registro dos pesquisadores).
\end{abstract}

De outro lado, por meio de trocas de correspondências, aos poucos as mentoras se sentiram mais à vontade para solicitar ou ofertar auxílio. O uso das correspondências, vistas como reservadas, sugere a tentativa de não tornar público para todos os membros do grupo as lacunas nas bases de conhecimento, a despeito da constatação de que nenhum formador sabe a totalidade de conhecimentos necessários para exercer o papel de mentor.

Como há uma grande preocupação em relação a interação das Pi com as mentoras, cada mentora relatou sobre o desenvolvimento de seu trabalho, de suas expectativas, de suas frustrações e de suas conquistas. Esta troca de experiências foi muito produtiva. Ajudou a enxergar o que consideramos problemas sobre outro aspecto. Muitas vezes, o que uma mentora fala dá ideia para outra mentora de como proceder. (Carol)

Penso também que a interação do grupo ao compartilhar seus conhecimentos e saberes foi um fator de destaque para a aprendizagem de novos procedimentos - o trabalho em parceria permite que quem ensina também aprenda ao ter que rever seus conceitos e sistematizar seus conhecimentos - e o desenvolvimento de atitudes - respeito, solidariedade e diálogo diante da convivência com pessoas diferentes. (Maria Imaculada)

\section{- Divergir $\times$ compartilhar crenças}

Ao longo do processo de desenvolvimento do Programa de Mentora, notaram-se divergências entre o pensamento manifesto pelas mentoras e os expressos pelas professoras iniciantes, como também entre as próprias mentoras. Essas divergências resultaram, algumas vezes, em discussões acaloradas entre as mentoras. 
Nesse dia, a Dirce fez a apresentação do trabalho que desenvolveu com sua Pi. Foi muito enriquecedor. Pude perceber que não estou agindo muito diferente do que ela. Fiquei mais tranquila. Mas, em certos momentos, percebo cada vez melhor que temos que acertar algumas arestas e esclarecer alguns procedimentos. Por exemplo: sobre produção e correção coletiva, ela disse que poderia aplicar um texto e que não precisaria devolver o mesmo para os alunos, utilizando este diagnóstico somente para si. Eu não concordo, eu acredito que todo trabalho desenvolvido pelo aluno deve ter retorno. Ele tem o direito de saber onde está errando, onde deve melhorar (...). (Carol)

Observando-se que um dos pressupostos foi o de conceber que as crenças podem funcionar como lentes que possibilitam a compreensão do processo de ensino e aprendizagem e a definição dos objetivos de ensino, entre outros aspectos, verifica-se que, quando algumas dessas ideias não são revisadas, podem se converter em ferramentas que distorcem a realidade, dificultando o entendimento adequado dos fatos e conceitos. Essas ocorrências, quando identificadas, exigiram que as pesquisadoras gerenciassem conflitos e criassem estratégias para seu enfrentamento, o que foi altamente produtivo, uma vez que permitiu a construção e a análise das diferentes posições e o espaço para as vozes discordantes.

\section{Algumas IDEIAS FINAIS}

A construção de uma comunidade de aprendizagem docente foi um processo complexo, em que o diálogo colaborativo possibilitou a exploração de valores, crenças, pressupostos e conhecimentos numa perspectiva de desenvolvimento profissional dos envolvidos. E as tensões observadas funcionaram frequentemente como alavancas para novos conhecimentos. O diálogo sobre as práticas favoreceu o abandono de modelos experimentados, ou construídos em outros contextos educativos, e percebidos como inadequados para serem adotados num programa via internet voltado para a formação de professores iniciantes. Observou-se a configuração de alguns subgrupos de participantes que interagiam mais intensamente entre si, em especial por meio de correspondências, circunscrevendo desse modo o alcance das mudanças e da exposição do que não sabiam.

No que respeito a essa limitação, confirmou-se que os conhecimentos construídos na comunidade de mentoras e pesquisadoras apresentaram as seguintes características: eram situados, envolveram diversos processos de interação social e eram distribuídos, no sentido de que nenhum membro do grupo detinha a totalidade dos conhecimentos exigidos para o desenvolvimento dos objetivos do programa. Esse foi um aspecto chave ratificado pelo grupo, que, aos poucos, passou a valorizar o exame coletivo do conhecimento profissional de cada uma de suas participantes no sentido de promover a construção de novos conhecimentos por parte dos outros membros do grupo (HARGREAVES, 1999). Parece clara a importância de a cultura colaborativa aceitar e investir na diversidade de conhecimentos e concepções, encorajar a expressão do discurso profissional e a troca de ideias, bem como mapear os conhecimentos profissionais comuns e as lacunas existentes numa comunidade de profissionais.

A duração dos processos de construção e desenvolvimento de uma comunidade de mentoras e de identidades profissionais de seus membros é fator relevante. Levando-se em conta a necessidade de estabelecimento de relações de confiança, de uma base compartilhada de conhecimentos profissionais e a construção de identidade de formador, o desenvolvimento de programas de mentoria que contem com grupos de formadores devem levar em conta a necessidade de um período temporal para que tais aspectos sejam estabelecidos e consolidados. À luz dos resultados positivos obtidos entre as professoras iniciantes acompanhadas e as professoras experientes que se transformaram em mentoras, têm destaque as reuniões semanais entre mentoras e pesquisadoras e as correspondências trocadas (entreelas e as mentoras e iniciantes). Essas atividades podem ser consideradas fonte poderosa de aprendizagem profissional a despeito das tensões observadas.

Compreender como as comunidades de aprendizagem profissionais de professores oferecem recursos intelectuais, sociais e materiais voltados para aprendizagem docente e para o desenvolvimento de práticas renovadas é um desafio. E este pode ser superado com a compreensão das variáveis envolvidas, em especial das tensões resultantes das interações sociais entre profissionais voltados para um mesmo objetivo.

\section{REFERÊNCIAS}

ACHINSTEIN, B.; ATHANASES, S. Z. Focusing new teachers on diversity and equity: toward a knowledge base for mentors. Teaching and Teacher Education, v. 21, p. 843-862, 2005. $<$ http://dx.doi.org/10.1016/j.tate.2005.05.017>.

BERLINER, D. Learning about and learning from expert teachers. International Journal of Educational Research, v. 35, n. 5, p. 463-482, 2001. <http://dx.doi.org/10.1016/S08830355(02)00004-6>.

BORKO, H.; PUTNAM, R. Learning to teach. In: BERLINER, D. C. CALFEE, R. C. (Eds.). Handbook of Educational Psychology. New York: McMillan, 1996. p. 673-708.

CARROL, D. Learning through interactive talk: a schoolbased mentor teacher group as a context for professional 
learning. Teaching and Teacher Education, v. 21, p. 4457-473, 2005. http://dx.doi.org/10.1016/j.tate.2005.03.005

CLARK, C. et al. Collaboration as dialogue: teacher and researchers engaged in conversation and professional development. American Educational Research Journal, v. 33, n. 1, p. 193-232, 1996. http://dx.doi.org/10.3102/ 00028312033001193

CLARK, C. et al. Continuing the dialogue on collaboration. American Educational Research Journal, v. 37, n. 4, p. 785-791, 1998. http://dx.doi.org/10.3102/00028312035004785

COCHRAN-SMITH, M.; FRIES, K. Researching teacher education in changing times: politics and paradigms. In: COCHRAN-SMITH, M.; ZEICHNER, K. M. (Eds.). Studying Teacher Education. The Report of the AERA Panel on Research and Teacher Education, Mahwah, NJ: Lawrence Erlbaum Associates, 2005.

COLE, A. L.; KNOWLES, J. G. Teacher development partnership research: a focus on methods and issues. American Educational Research Journal, v. 30, n. 3, p. 473-495, 1993.

COCHRAN-SMITH, M. Learning and unlearning: the education of teacher educators. Teaching and Teacher Education, v. 19, p. 5-28, 2003. http://dx.doi.org/10.1016/ S0742-051X(02)00091-4

DARLING-HAMMOND, L.; BARATZ-SNOWDEN, J. (Eds.). Preparing teachers for a changing world. What teachers should learn and be able to do. The National Academy of Education.San Francisco: Jossey-Bass, 2005.

DAY, C. Pasión por enseñar. Madri: Narcea S.A. Ediciones, 2007.

FAIRBANKS, C. M.; DUFFY, G. D.; FAIRCLOTH, B. S.; HE, Y; LEVIN, B.; ROHR, J.; STEIN, C. Beyond knowledge: exploring why some teachers are more thoughtfully adaptive than others, Journal of Teacher Education, v. 61, n. 1-2, p. 61-171, 2010. http://dx.doi.org/10.1177/0022487109347874

GALLUCCI, C. Theorizing about responses to reform: the role of communities of practice in teacher learning. An occasional paper. Center for the Study of Teaching and Policy, 2003. Disponível em: <www.ctpweb.org>. Acesso em: 20 ago. 2005 .

GATTI, B. A.; BARRETO, E. S. S.; ANDRÉ, M. E. D. A. Políticas docentes no Brasil: um estado da arte. Brasília: Unesco, 2011.

GROSSMAN P.; WINEBURG, S; WOOLWORTH, S. What makes teacher community different from a gathering of teachers. An occasional paper. Center for the Study of Teaching and Policy, 2000. Disponivel em: $<$ www.ctpweb.org $>$. Acesso em: 14 jan. 2006.

HAMMERNESS, K. et al. How teachers learn and develop. In: DARLING-HAMMOND, L.; BRANSFORD, J. (Eds.). Preparing teachers for a changing world. What teachers should learn and be able to do. The National Academy of Education, San Francisco: Jossey-Bass, 2005. p. 358-89.
HARGREAVES, D. (The knowledge-creating school. British Journal of Educational Studies, v. 47, n. 2, p. 122-144, 1999. 1999. http://dx.doi.org/10.1111/1467-8527.00107

KENNEDY, M. Knowledge and vision in teaching. Journal of Teacher Education, v. 57, p. 205-211, 2006. http://dx.doi. org/10.1177/0022487105285639

KNOWLES, J. G.; COLE, A. L.; PRESSWORD, C. S. Through preservice teachers' eyes: exploring field experiences through narrative and inquiry. Nova Scotia, Canada: Backalong Books, Halifax, 2008.

MARCELO, C. Las tecnologías para la innovación y la práctica docente. Revista Brasileira de Educação, v. 18, n. 52, jan.-mar. 2013. http://dx.doi.org/10.1590/S1413-24782013000100003

MIZUKAMI, M. G. N.; REALI, A. M. R.; LIMA, E. L.; TANCREDI, R. M. S. P.; MELLO, R. R.; REYES, C.; MARTUCCI, E. Escola e aprendizagem da docência: processos de investigação e formação. São Carlos, SP: EDUFScar, 2010.

MURRAY, J.; MALE, T. Becoming a teacher: evidence from the field. Teaching and Teacher Education, v. 21, n. 2, p. $125-142,2005$.

PACHECO, J. A. B.; FLORES, M. A. Formação e avaliação de professores. Porto: Porto Editora, 1999.

REALI, A.M.M.R.; TANCREDI, R.M.S.P. Programa de Apoio aos Educadores: Espaço de Desenvolvimento Profissional. Projeto de extensão vinculado ao Núcleo UniversidadeEscola e ao Programa de Apoio à Extensão Universitária Voltado às Políticas Públicas - PROEXT2003/SESu-MEC., 2003.

REALI, A. M. M. R.; TANCREDI, R. M. S.; MIZUKAMI, M. G. N. Desenvolvimento profissional de professores iniciantes em um programa de mentoria online: experiências de ensino e aprendizagem (EEA) como ferramentas investigativas e formativas. Revista e-Curriculum, v. 12 n. 01, jan./abr. 2014. Disponível em: <http://revistas.pucsp.br/index.php/ curriculum>. Acesso em: 13 maio 2015.

SHULMAN, L. S. Knowledge and teaching: foundations of the new reform. Harvard Educational Review, v. 57, n. 1, p. 1-22, 1987. http://dx.doi.org/10.17763/haer.57.1.j463w79r56455411

VAILLANT, D. Formação de formadores: estado da prática. Documentos de trabalho, n. 25. Preal (Programa de Promoção da Reforma Educativa na América Latina e Caribe), 2003. Disponível em: <http://www.preal.org/docs-trabajo/ VaillantN31.pdf>.

VILLEGAS-REIMERS, E. Teacher professional development: an international review of literature. Paris: Unesco/ International Institute for Educational Planning, 2003.

WENGER, E.; WHITE, N.; SMITH, J. D. Digital habitats: stewarding technology for communities. CPsquare Portland, OR, 97206, 2009.

Submetido em: 30/07/2013

Aprovado em: 03/09/2015 